\title{
O semanário Marcha, Carlos Quijano e a configuração de um circuito cultural de resistência no Uruguai (anos 1960-70) (40 $^{6}$
}

\author{
Mariana Villaça \\ mariana.villaca@unifesp.br \\ Doutora em História Social pela USP \\ Professora da graduação e pós-graduação em História, com ênfase em História da América \\ Independente, pela Universidade Federal de São Paulo
}

\begin{abstract}
Resumo: O semanário uruguaio Marcha, principal publicação da editora de mesmo nome, dirigida por Carlos Quijano, exerceu papel fundamental na consolidação de um circuito de resistência cultural naquele país, no contexto de acirramento do autoritarismo que marcou o governo de Pacheco Areco e culminou na instauração de um regime civil-militar em 1973. Partimos da hipótese de que Marcha exerceu papel de agente e formulador de uma política cultural responsável pela sedimentação desse circuito e de uma hegemonia cultural de esquerda. No presente trabalho, focamos a importância da trajetória de Carlos Quijano para a compreensão histórica do perfil de Marcha e da política cultural empreendida por esse organismo. Também destacamos, a fim de mapear a natureza dessa política cultural, alguns eventos e ações apoiados por Marcha que contribuíram, por um lado, para consolidar seu papel de pólo de resistência política e, por outro, reforçar vínculos culturais com países vizinhos, em uma perspectiva de afirmação do latino-americanismo, o qual, a partir de então, se torna um vetor influente na ressignificação da identidade uruguaia experimentada nos anos 1970.
\end{abstract}

Palavras chave: Semanário Marcha, Regime Civil-Militar Uruguaio; Resistência Cultural

\section{El semanario Marcha, Carlos Quijano y la configuración de un circuito de resistencia cultural en Uruguay (1960-1970)}

Resumen: El semanario uruguayo Marcha, la publicación principal del editorial de mismo nombre, dirigido por Carlos Quijano, jugó un papel clave en la consolidación de un circuito de resistencia cultural en el país, en el contexto de intensificación del autoritarismo que caracterizó el gobierno Pacheco Areco y culminó en el establecimiento de un régimen civil-militar en 1973. Nuestra hipótesis es que Marcha jugó papel agente y formulador de una política cultural responsable por sedimentar este circuito y la hegemonía cultural de la izquierda. En este trabajo, nos centramos en la importancia de la trayectoria de Carlos Quijano para la comprensión histórica del perfil Marcha y la política cultural llevada a cabo por ese organismo.

\footnotetext{
${ }^{640}$ Este artigo é resultado da pesquisa intitulada "As edições Marcha e a constituição de um circuito cultural de resistência política frente o acirramento do autoritarismo no Uruguai (1967-1974)" que contou com Auxílio Regular da Fapesp entre março de 2015 e abril de 2017.
} 
También hay que señalar, con el fin de trazar la naturaleza de esa política cultural, algunos eventos y acciones apoyados por Marcha que contribuyeron, por un lado, para consolidar su papel de polo de resistencia política y, por otro, para fortalecer los lazos culturales con los países vecinos en una perspectiva de afirimación del latinoamericanismo, el cual, a partir de entonces, se convierte en un vector de influencia en la reformulación de la identidad uruguaya experimentada en la década de 1970.

Palabras claves: Semanário Marcha, Régimen Civil-Militar Uruguayo, Resistencia Cultural

Neste trabalho apresentamos algumas considerações acerca do papel do semanário Marcha na constituição, nos anos 1960, de um circuito de resistência cultural e política no Uruguai, em um período de forte acirramento do autoritarismo que antecedeu o golpe militar nesse país. Primeiramente, cabe fazermos uma breve apresentação das edições Marcha, que além do mencionado semanário, se ramificavam em publicações de outros formatos, todas impressas em uma gráfica própria: os Cuadernos de Marcha (1967-1974), revistas monotemáticas mensais dedicadas a tratar de temas políticos ou culturais bastante específicos (como a guerra do Vietnã, a revolução Cubana, independência e formação da nação no Uruguai, ou a vida e obra de personalidades como José Enrique Rodó, Marx, Benedetto Crocce) e a coleção editorial denominada Biblioteca de Marcha (1969-1974) que publicou livros autorais e coletâneas, assinados principalmente por intelectuais uruguaios.

O semanário Marcha, publicado em geral às sextas-feiras era constituído, em média, por 30 páginas, e circulou entre junho de 1939 a novembro de 1974, totalizando 1676 edições. Essa e outras publicações da editora Marcha, em suas várias versões, conferiam grande ênfase a temáticas da atualidade relacionadas à política e à cultura no mundo contemporâneo. Cabe destacar que a editora Marcha já foi objeto de diversos estudos, dentro e fora do Uruguai ${ }^{641}$,

\footnotetext{
641 ROCCA, Pablo. 35 años en Marcha. Crítica y literatura en Marcha y en el Uruguay (1939-1974). Montevideo: Intendencia Municipal de Montevideo, 1992; MORAÑA, Mabel; MACHÍN, Horacio. (Eds) Marcha y America Latina. Pittsburgh: Instituto Internacional de Literatura Iberoamericana, 2003. PIÑEYRÚA, Pilar. "Las tapas y titulares del semanário Marcha: una puerta grande a la argumentación." Buenos Aires, IV Jornadas de Historia de las Izquierdas, 14-17 noviembre 2007. GREGORY, Stephen. Intelectuals and a Left Politics in Uruguay 1958-2006. Frustrade Dialogue. Portland: Sussesx Academica Press, 2009. REIS, Mateus Fávaro. Políticas da leitura, leituras da política: uma história comparada sobre os debates político-culturais em Marcha e Ercilla (Uruguai e Chile, 1932-1974). Tese de doutorado. Belo Horizonte: Universidade Federal de Minas Gerais, 2012. PINO, Mirian. "El semanario Marcha de Uruguay: uma genealogia de la crítica de la cultura en América Latina". Revista Crítica Literaria Latinoamericana, XXVIII, 56, 2002, p. 141-156. LACRUZ, Cecilia. "La experiencia del semanario Marcha y el cine político en Uruguay". In: CABEZAS VILLALOBOS, O; ANSA GOICOECHEA, E. (orgs) Efectos de imagen. ¿Qué fué y
} 
sendo alguns desses trabalhos acadêmicos de fôlego, voltados especificamente aos Cuadernos de Marcha $^{642}$. Esses estudos, sejam voltados ao semanário (nosso principal objeto de interesse), aos Cuadernos, ou à coleção Biblioteca de Marcha, costumam ressaltar, além do visível compromisso com a abordagem de debates e fenômenos atuais, sua tendência em expressar um jornalismo opinativo, ancorado em ensaios e artigos assinados por grandes nomes da intelectualidade nacional e latino-americana ${ }^{643}$. Ao folhear as páginas de suas publicações nota-se que Marcha destinava espaço restrito à publicidade, postura que condiz com a pretensão de sua direção em nutrir certa independência financeira e política. Corrobora essa opção e ilustra uma situação de constante instabilidade financeira o fato de muitos de seus colaboradores não receberem pagamento por seus textos publicados ${ }^{644}$. Mesmo marcado por alguma precariedade econômica, as publicações de Marcha notabilizaram-se pela qualidade de seus ensaios e reportagens, escritos para um público leitor que possuísse boa escolarização e repertório cultural condizente com o estilo - por vezes erudito- de seus colaboradores.

No Uruguai predomina uma memória celebrativa e heróica da história de Marcha. Essa envolve particularmente o semanário, sua publicação de maior popularidade, com uma tiragem de cerca de 30.000 exemplares. Tal periódico desempenhou, principalmente nos seus últimos anos de existência, uma oposição política ousada e aguerrida às ditaduras na América Latina e ao imperialismo norte-americano. Em suas páginas, no final dos anos 1960 e

qué es el cine militante? Santiago: LOM Ediciones / Universidad Metropolitana de Ciencias de La Educacion, 2014, p. 23-39.

642 COUTO, Cristiano Pinheiro de Paula. Cuadernos de Marcha (Primeira Época, Montevidéu, 1967-1974): uma "trincheira de ideias" desde o Uruguai para o mundo. Florianópolis, 2008, 128p. Dissertação (Mestrado em História) - Programa de Pós-Graduação em História, Universidade Federal de Santa Catarina. COUTO, Cristiano Pinheiro de Paula. Intelectuais e exílios. Confronto de resistências em revistas culturais. Encontros com a Civilização Brasileira, Cuadernos de Marcha e Controversia (1978-1984) Tese de Doutorado em História, Porto Alegre: Universidade Federal do Rio Grande do Sul, 2013. PEIRANO BASSO, Luísa. Marcha de Montevideo y la formación de la conciencia latinoamericana a través de sus cuadernos. Buenos Aires: Ediciones B, 2001.

643 O semanário Marcha, além de publicar de forma regular artigos de seu diretor Carlos Quijano e de alguns colaboradores fixos como Arturo Ardao e Julio Castro, contou em sua equipe editorial, ao longo de suas décadas de existência com intelectuais/artistas prestigiados no país como Carlos Martinez Moreno, Mario Benedetti, Joaquin Torres Garcia, Zelmar Michelini, Eduardo Galeano, Angel Rama, entre outros. Nomes latino-americanos de peso, principalmente nos campos da literatura e dos estudos políticos, também figuraram em suas páginas: Octavio Paz, Miguel Angel Asturias, Salvador Allende, Josué de Castro, Pablo Neruda, José María Arguedas, Darcy Ribeiro são alguns exemplos.

${ }^{644}$ Essa prática do colaboracionismo não remunerado que se observa em Marcha, segundo Pilar Piñeyrúa não era um fenômeno exclusivo a esse periódico: mostra-se constante no jornalismo de opinião, nos anos 1960. PIÑEYRÚA, op. cit., p. 17. 
enquanto pode circular, nos anos 1970, é nítido o discurso de combate ao autoritarismo no país e o apelo à resistência popular contra a institucionalização da ditadura. Corroborando com a construção do discurso histórico sobre o Marcha, somam-se à contundente postura de oposição as agruras posteriormente vividas por seu diretor, Carlos Quijano, que faleceu durante o exílio no México, em 1984, bem com as desventuras de sua equipe editorial, marcadas por prisões e perseguições, ante a disposição de manter ativa parte das publicações no exterior, durante a ditadura ${ }^{645}$. Naturalmente, para compreendermos a visão heroica e algo nostálgica que recobre o nome Marcha, não apenas no Uruguai como em vários países da América Latina, também deve se levar em conta o peso da derrota das esquerdas naquele país e o inevitável processo de heroicização que marca a memória construída acerca dos nichos de resistência política.

Se esses elementos já nos parecem suficientes para a compreensão histórica da aura quase mítica que se consagrou em torno de Marcha, outros fatores ainda podem ser considerados para dimensionarmos com mais propriedade o lugar dessa editora junto à história do movimento de resistência à ditadura uruguaia. É este nosso propósito a seguir: destacar algumas das ações de política cultural empreendidas por Marcha, a partir de um recorte que privilegia as informações impressas nas páginas do semanário, relatos de memória e a historiografia uruguaia recente, buscando dimensionar a atuação desse órgão de imprensa na sociedade.

\section{Carlos Quijano e a configuração de uma política cultural latino-americanista}

Durante seu longo período de existência, o semanário Marcha foi principalmente dirigido pelo político e intelectual Carlos Quijano (1900-1984), que conduzia o jornal imprimindo fortes traços de seu gosto pessoal e de suas preferências políticas à escolha das capas, pautas, reportagens e colaboradores. Dentre as bandeiras defendidas por Quijano que

\footnotetext{
645 Vale destacar que após o fechamento do semanário Marcha no Uruguai, e o fim da hoje chamada Primeira Época dos Cuadernos (1967-1974, quando foram publicados no Uruguai 78 números), essa revista voltou a ser editada, sob condições precárias, no México, entre 1979 e 1984 (período denominado Segunda Época), e novamente no Uruguai entre 1985 e 2001 (Terceira Época). COUTO, Cristiano Pinheiro de Paula. Cuadernos de Marcha (Primeira Época, Montevidéu, 1967-1974): uma "trincheira de ideias" desde o Uruguai para o mundo. Florianópolis, 2008, p. 25-26.
} 
ecoaram ostensivamente no semanário, podemos encontrar o antiimperialismo, acompanhado do desejo de debater - e incensar - a identidade latino-americana. São freqüentes os artigos e as produções culturais apoiadas por Marcha que reiteram a relação entre identidade nacional e latino-americana, algumas vezes também fundida à bandeira terceiro-mundista. Assim, poderíamos afirmar que Marcha contribui substancialmente para um processo de redimensionamento da identidade nacional, até então muito marcada pela perspectiva otimista do "excepcionalismo" uruguaio, no qual nos deteremos a seguir.

Precisamos esclarecer que certas idéias ou "bandeiras" - como o antiimperialismo e o latino-americanismo, sumamente complementares - longe de serem exclusivas a Carlos Quijano ou a sua editora, foram marcas identitárias expressivas da geração de intelectuais à qual este é identificado, a chamada "Geração de 45", também conhecida como "la generación crítica". Esse termo foi cunhado por Angel Rama, que a localiza temporalmente entre 1939 e $1963^{646}$. Especialmente ativa nos anos 1950-60, ela foi constituída, além de Quijano, por nomes como Arturo Ardao, Juan Carlos Onetti, Carlos Real de Azúa, Emir Rodriguez Monegal, entre outros intelectuais. Essa geração levantou publicamente a questão da "insularidade" do país, metaforizando seu isolamento, suas limitações como país pequeno, oprimido e comprimido pelas fronteiras com o Brasil e a Argentina ${ }^{647}$ A chamada orientalidad, essência da identidade nacional do uruguaio (que até hoje se auto-designa comumente como oriental, fazendo jus ao nome oficial da República e ao processo histórico de formação do Estado) era também problematizada por essa geração ao destacar o quanto a sociedade havia se constituído menos pelo povo nativo e mais por uma população "transplantada", imigrante e fiel a determinadas marcas identitárias européias. Nas obras dessa geração também percebemos ressoarem os ecos da decadência econômica acompanhando o questionamento da imagem de "Suíça da América Latina". Tal imagem era icônica da concepção de que o Uruguai era um país excepcional no continente (laico, branco, republicano, culto, com boa qualidade de vida e eficiente estado de bem-estar social). Essa visão romântica havia sido

\footnotetext{
${ }^{646}$ RAMA, Angel. La generación crítica. Montevideo: Editorial Arca, 1972. Para saber mais sobre esse intelectual que foi um dos mais importantes críticos literários latino-americanos, ver: MARTINEZ, Tomas Eloy. "Angel Rama o la critica como gozo". Revista Iberoamericana, Pittsburgh, v. LII, no 135-136, p. 645-664, abril/septiembre de 1986. RODRIGUES, Joana de Fátima. Nas páginas do jornal. Angel Rama e Antonio Candido: críticos literários na imprensa. São Paulo. Doutorado em Letras, EFLCH-USP, 2012.

${ }^{647}$ ACHUGAR, Hugo; CAETANO, Gerardo (orgs). Identidad uruguaya: ¿imito, crisis oafirmación? 3a ed. Montevidéu: Trilce, 1992.
} 
muito endossada, ao longo da história uruguaia, pelo nacionalismo da "Geração de 1880" e pela corrente política denominada batllismo ${ }^{648}$. Esses intelectuais, que haviam gozado os benefícios de uma educação de alta qualidade, laica e universalista; e comumente haviam completado sua formação em universidades européias ${ }^{649}$, percebiam o Uruguai dos anos 1950-60 como um país endogâmico, edulcorado por décadas de vigência de um discurso ultranacionalista, agora percebido como forjado, superficial. Essa postura de negação coincidia com o perfil político dessa geração que, a grosso modo, se mostrava desencantada com os partidos tracionais (Colorado e Nacional), flertava com o socialismo mas se mostrava, sobretudo, defensora da democracia, do pluralismo.

Esses traços todos podem ser encontrados em Carlos Quijano, originalmente um afiliado do Partido Nacional, que buscara construir uma alternativa política para si próprio e fundara, por meio de uma cisão no interior desse mesmo partido a Agrupación Nacionalista Demócrata Social (ANDS) em 1929, dela desligando-se, assim como do próprio Partido Nacional, em 1958, por razões que nos eximiremos de explorar face os limites desse artigo.

Ao longo de sua militância partidária, Quijano chegou a ser deputado (entre 1928 e 1931), período no qual intensificou sua atuação no meio jornalístico ao fundar o diário $E I$ Nacional (1930). Essa experiência inaugurou uma fase empreendedora que se desdobrou, contudo, na opção pelos semanários. Assim, pouco depois fundava o semanário Acción (19321938) e já no fim da década, o seu periódico mais conhecido: Marcha (1939). Em todas essas publicações o debate político nacional, as análises e considerações sobre a identidade uruguaia, os rumos do país e as perspectivas para a América Latina se faziam presentes.

Quijano, como denuncia o nome da legenda que fundou nos anos 1920, nutria inclinações socialistas. Conhecia bem o marxismo, mas sustentava uma franca disposição, compartilhada com outros colegas da mesma geração, em defender a democracia e o

\footnotetext{
648 Em referência às idéias e práticas políticas empregadas por José Battle y Ordoñez (1856-1929), presidente do Uruguai em 1903-1907 e 1911-1915. Ver: PANIZZA, Francisco. Batllismo y después. Pacheco, militares y tupamaros en la crisis del Uruguay batllista. Montevideo: Ediciones de La Banda Oriental, 1990.

${ }^{649}$ Quijano, por exemplo, formou-se em direito no Uruguai e estudou Economia e Ciências Políticas na Sorbonne, oportunidade em que participou da Asociaición Genenral de Estudiantes Latinoamericanos (AGELA), na qual teve contato com jovens intelectuais de váris partes do continente como Miguel Angel Asturias, Juan Antonio Mella, Victor Haya de la Torre, entre outros, e publicou, em 1927, um livro intitulado Nicaragua, un ensayo sobre el imperialismo de los Estados Unidos. PREGO GADEA, Omar. "Carlos Quijano, una vida en el siglo". Website da Fundacion Lolita Rubial. Disponível em http://www.fundacionlolitarubial.org/bioquija.html. Acesso em 25 de fevereiro de 2017.
} 
desenvolvimentismo ${ }^{650}$. Em um de seus depoimentos, advogou que a "fórmula de ação" em que acreditava resumia-se em três palavras: "nacionalismo, socialismo e democracia"651. Dizia-se também defensor do humanismo e da liberdade, em nome dos quais havia sido opositor da ditadura de Gabriel Terra (1933 - 38) e vinha condenando o dogmatismo presente nos países socialistas.

Não é nossa intenção nos estendermos em demasia sobre a formação pessoal e política de Quijano, mas acreditamos que sua trajetória seja importante para compreendermos determinadas características de Marcha e da política cultural encampada por sua direção. Uma dessas já mencionadas características é o latino-americanismo, marca recorrente nas edições e no labor de Quijano como editor e jornalista, que deve ser entendida não apenas em função do contexto de época mas também como parte do arcabouço ideológico de sua formação intelectual desde os tempos de juventude. Nessa época, o então estudante Quijano, influenciado pelo pensamento americanista de José Enrique Rodó, tornouse, em 1917, um dos fundadores do Centro de Estudios Arie/652. Pouco depois, participou das lutas universitárias no Uruguai, que se seguiram ao Cordobazo argentino, período em que cultivou um latino-americanismo de contornos políticos muito marcados.

Sua disposição para o ativismo político e jornalístico nos ajudam a entender a motivação em trazer para as páginas do semanário Marcha (e inclusive para a concepção editorial dos Cadernos de Marcha) temas polêmicos em perspectiva regional, como a "viabilidade" econômica do Uruguai ante seus vizinhos; as vicissitudes do socialismo cubano considerando os "erros e acertos" daquela Revolução; a necessidade de uma arte autêntica que melhor correspondesse à realidade da América Latina, entre outros assuntos cuja abordagem demonstrava esse anseio de refletir sobre nossas idiossincrasias.

A temática da Revolução Cubana, por exemplo, vemos presente em muitas matérias e artigos, alguns dos quais voltados às acusações da existência de perseguição política aos

\footnotetext{
650 REAL DE AZÚA, Carlos. “Carlos Quijano (1900)” In: Antología del Ensayo Uruguayo Contemporáneo, Tomo II. Departamento de Publicaciones de la Universidad de la República, Montevideo, Uruguay, 1964, p. 322.

${ }^{651}$ Cuadernos de Marcha, Tercera época, Montevideo, junio de 1987, N 20, p. 3. Citado por Arturo Ardao na Introducción do tomo I das obras de Carlos Quijano, Montevideo, Ed. de la Cámara de Representantes, 1989. Apud: PREGO GADEA, Omar. "Carlos Quijano, una vida en el siglo". Website da Fundacion Lolita Rubial. Disponível em http://www.fundacionlolitarubial.org/bioquija.html. Acesso em 25 de fevereiro de 2017.

652 Há certa polêmica sobre o quanto o arielismo foi marcante na formação de Quijano. Os estudiosos uruguaios Gerardo Caetano e José Pedro Rilla relativizam essa influência, enfatizando que Quijano se distanciou do arielismo ao dedicar-se ao estudos de economia e ao abraçar a luta política, enquanto Arturo Ardao ressalta a importância desse contato para sua convicção antiimperialista.
} 
intelectuais cubanos pelo governo de Fidel Castro ${ }^{653}$. Nesse caso, é patente a disposição da direção de Marcha em apoiar o governo cubano, ainda que condenasse o cerceamento à liberdade de expressão em Cuba. Uma série de artigos sobre o mesmo tema, em maio de 1971, abordou o famoso "caso Padilla". 654 Um dos jornalistas uruguaios que participaram da cobertura desse caso foi Eduardo Galeano, intelectual que também chegou a dirigir a Redação de Marcha e apresentava uma defesa contundente das ações do governo cubano, sugerindo que os Estados Unidos e parte da intelectualidade não comprometida com a defesa do socialismo eram responsáveis por uma campanha de difamação daquele governo. Essa postura indica tensões presentes no seio da equipe de Marcha, deflagradas por uma disposição da direção em combinar o apoio à expansão da revolução na América Latina, o antiimperialismo e a defesa das liberdades individuais. Eduardo Galeano, um dos colaboradores freqüentes de Marcha, expressava um latino-americanismo ainda mais combativo que o de Quijano, e adotava, como aquele, um estilo de escrita híbrido, em que fundia ensaísmo jornalístico, marxismo, teses economicistas e determinada visão de história sob o prisma da Teoria da Dependência. Não casualmente, Galeano pouco depois se dedicaria a escrever um volumoso trabalho sobre a história da América Latina que se tornaria um verdadeiro best-seller regional: o livro As Veias Aberta da América Latina ${ }^{655}$.

Fatos políticos, movimentos sociais e os diversos acontecimentos internacionais envolvendo Cuba, Guerra do Vietnã, ditaduras, movimento estudantil, lutas anticoloniais ou reivindicações em prol da defesa dos direitos humanos, entre tantas bandeiras, impunham, nos anos 1960 e 1970, pautas e posicionamentos que em Marcha se tornaram cada vez mais explícitos, como no caso relatado anteriormente. Quijano, desde seu rompimento com o Partido Nacional, se aproximara mais das esquerdas, buscando estreitar vínculos com intelectuais que passariam a imprimir em suas contribuições, tal como Galeano, um tom explícito de engajamento político ao jornal.

\footnotetext{
653 BENEDETTI, Mario. "Situación actual de la cultura cubana." Marcha núm. 1431, 27 de diciembre de 1968, p. 15-20.

654 Ver Marcha, núm. 1545, 23/05/1971. Para entender o que foi o Caso Padilla, ver: MISKULIN, Silvia. Os intelectuais cubanos e a política cultural da Revolução. São Paulo: Alameda, 2009.

${ }^{655}$ Em entrevista publicada em Marcha, Galeano fala do objetivo do livro: "poner la economia política al alcance del lector medio". RUFFINELLI, Jorge. "Entrevista con Eduardo Galeano. El escritor en el proceso americano." Marcha núm. 1555, 06/08/1971, p. 30-31. Ver mais sobre essa publicação em: OLIVEIRA, Alexandre Queiroz. "Quando se rompe o silêncio: o livro As Veias Abertas da América Latina e sua trajetória no Brasil". Temporalidades - Revista Discente do Programa de Pós-Graduação em História da UFMG Vol. 5, n. 1, Jan/Abr - 2013, p. 6-28.
} 
Em se tratando do perfil político de Marcha, mais saliente nesse período que em outras fases do semanário, vale ressalvarmos que, apesar do notório personalismo imposto por Carlos Quijano, não nos parece acertado absolutizar esse vínculo, uma vez que encontramos divergências e até pluralidade de opiniões dentre os ensaios ali publicados. Assim, exerceram também papel importante na configuração do perfil de Marcha, os colaboradores assíduos e os chefes de Redação que acompanharam Quijano, a exemplo do jornalista Hugo Alfaro (19171996) ${ }^{656}$, que ocupou essa função entre 1945 e 1974, e que possuía clara influência na escolha das pautas e temáticas, bem como no patrocínio de iniciativas artísticas. A tendência em se associar umbilicalmente Marcha e Quijano provém, naturalmente, da memória consagrada a respeito da trajetória de vida desse intelectual e sua dedicação visceral ao periódico. 0 empenho notório de Quijano e os muitos esforços que empreendeu para manter a publicação sob a conjuntura de autoritarismo desde o Pachecato ${ }^{657}$ contribuíram para a indissociação de sua identidade à do periódico, relação muito presente nas memórias de seus colegas de trabalho, Carlos Real de Azúa e Alfaro. E essa imagem heróica de Quijano, logo após o fim da ditadura foi reconhecida e reafirmada pelo próprio governo da abertura em diversas ocasiões, começando pela transferência de seus restos mortais para o Panteão Nacional. ${ }^{658}$

Contudo, a faceta de Quijano que mais nos interessa, em nossa pesquisa, é a de formulador de política cultural ${ }^{659}$. Por meio das notícias referentes ao mundo dos espetáculos, por ele avalizadas para a publicação no semanário, temos indicações muito sugestivas de sua preocupação em explorar, nas artes, os potenciais dispositivos de conscientização política.

\footnotetext{
${ }^{656}$ Alfaro também foi crítico de cinema e entusiasta da Frente Ampla. Fundou o semanário Brecha, em 1985, com Mario Benedetti, Eduardo Galeano, entre outros remanescentes de Marcha. Escreveu os livros Navegar es necesario (sobre o semanário Marcha e seu diretor, Carlos Quijano) e Mario Benedetti: detrás de un vidrio claro. 657 Nome dado ao período de governo do presidente Jorge Pacheco Areco (1967-1972) Ver: PADRÓS, Enrique Serra. Como el Uruguay no hay. Terror de Estado e Segurança Nacional. Uruguai (1968-1985): do Pachecato à ditadura civil-militar. Tese de doutorado em História, Porto Alegre, UFRGS, 2005.

${ }^{658} \mathrm{Em}$ "El 27 de junio de 1987, sus restos repatriados fueron trasladados con honores oficiales desde el Paraninfo de la Universidad hasta el Panteón Nacional, donde merecidamente descansan". LUPPI, Carlos. "Carlos Quijano: testigo y forjador de uma época. A 30 anõs de su fallecimiento". Caras y Caretas, Montevideo, 09 de junio de 2014. Disponível em: http://www.carasycaretas.com.uy/carlos-quijano-testigo-y-forjador-de-una-epoca/. Acesso em15 de fevereiro de 2017. Vale destacar, também como mostra do reconhecimento estatal de seus méritos como intelectual, que em 1989, a Cámara de Representantes de Montevidéu, publicou boa parte de suas obras, distribuídas em vários tomos.

${ }^{659}$ Considerarmos Quijano um formulador de política cultural à medida que seu perfil se enquadra na definição, proposta por Joaquin Brunner, de alguém que "intervém dentro de um circuito determinado não somente com o propósito de oferecer um produto simbólico, como também influenciar na orientação desse circuito, criar uma tradição artística determinada, combater uma escola oposta, criticar o governo com essa ação cultural." BRUNNER, J. J. América Latina: cultura y modernidad. México: Grijalbo/Conaculta, 1992, p. 253
} 
Assim, vemos que o semanário Marcha foi inegavelmente marcado pelo poder de decisão e pelas inclinações de seu diretor, como já frisamos, mas não apenas, uma vez que, atores diversos (individualmente ou organizados em pequenos coletivos) se envolviam na produção de artigos colaborativos e nas ações, junto a sociedade, que contavam com o apoio explícito do periódico.

Focamos a seguir justamente algumas ações que emanaram da direção de Marcha a fim de promover ou difundir eventos políticos e culturais - prática que contribuiu sobremaneira para consolidar a identidade política dessa editora.

\section{Trazendo a Patria Grande para dentro do Paisito}

Considerando sua circulação e popularidade, podemos afirmar que o semanário Marcha exerceu papel substantivo como formador de opinião junto a seu público leitor, aderindo a campanhas políticas muito representativas da oposição ao regime militar que já se avizinhava no começo da década de 1970. Foi o caso de sua participação no lançamento e na articulação da campanha pela Frente Ampla, coalizão de esquerda que procurou frear, sem sucesso, pelas vias democráticas o processo autoritário que redundou na instauração do regime civil-militar em $1973^{660}$. Como empresa de grande penetração no meio cultural, sua direção patrocinava (ou apoiava por meio de ampla divulgação), diversos eventos e expressões políticas e culturais, como se evidencia no caso do cinema, da música, da literatura e do teatro. Dessa maneira, explicitando seu engajamento político e exercendo intensamente seu potencial de promoção no campo artístico, a "marca" Marcha ${ }^{661}$, entre o final dos anos 1960 e o início dos anos 1970 acumulou forte capital simbólico no campo político-cultural, passando a ser encarada como sinônimo e pólo de resistência.

A política cultural ${ }^{662}$ promovida por Marcha mobilizava não apenas espaços estritamente vinculados à editora, caso de sua própria sede e sua gráfica, como também

\footnotetext{
${ }^{660}$ Sobre esse tema, ver o excelente estudo: FERREIRA, André Lopes. A unidade política das esquerdas no Uruguai: das primeiras experiências à Frente Ampla (1958-1973), Tese de doutorado em História, UNESP - Assis (São Paulo), 2011.

${ }^{661}$ Representada não apenas pelo nome sugestivo, mas pelo logotipo composto por um barco à vela e a inscrição (atribuída ao general romano Pompeu), que nele aparece a partir de 1967: Navigare Necesse, Vivere Non Necesse (Navegar é preciso, viver não é preciso).

662 Ao tratarmos de política cultural, a entendemos como um conjunto plural de ações que mobilizam a cultura e podem ser formuladas e/ou executadas por diferentes tipos de agentes (Estado, esferas governamentais,
} 
lugares informais que se prestassem a tal tipo de ousadia (projeções de filmes políticos, debates, etc) como igrejas situadas nos bairros periféricos, sindicatos, escolas, faculdades ${ }^{663}$. O grau de compromisso e de exposição pública com o evento ou a expressão artística que patrocinava era variável: Marcha organizou, diretamente, mini-cursos de ciências sociais, conferencias e mesas-redondas em sua sede, concursos literários, os Festivais de Cine de Marcha ${ }^{664}$ e uma cinemateca com documentários considerados "revolucionários"665. De forma menos explícita patrocinou espetáculos musicais, eventos de solidariedade a Cuba, temporadas teatrais, apresentações de canção de protestos e saraus. Chamam a atenção alguns eventos apoiados por Marcha que tinham caráter híbrido, sendo constituídos, por exemplo, por uma exibição de filme, seguida de um "pocket show" de algum músico ou um recital de poesia ${ }^{666}$. Essas sessões conjugadas muitas vezes aconteciam noite adentro, geralmente aos sábados, e eram conhecidas como "Trasnoches". $667 \mathrm{O}$ simples fato de ocorrerem madrugada adentro exalava uma conotação subversiva, underground, atraindo o público estudantil universitário com suas diversas tribos militantes que, nessas e em outras ocasiões, compartilhavam espaços e preferências artísticas a despeito de suas inclinações

instituições, indústria cultural, etc). Entendemos, também, que a política cultural deve ser estudada como um processo dinâmico, suscetível de interferências, reelaborações, conflitos e resistências. VILLAÇA, Mariana. Cinema Cubano. Revolução e Política Cultural. São Paulo: Alameda, 2010, p. 22-25.

${ }^{663}$ Em 1969, o Cine Club de Marcha noticiava exibições na Igreja Metodista del Uruguay, na sede da Juventud Judía Progresista e na Faculdade de Medicina. Ver: Marcha núm. 1451, 06/06/1969, p. 27. Algumas salas de bairro, mesmo precárias, também eram usadas. ALFARO, Hugo. "Lutecia: reportaje a um cine de barrio". Marcha núm. 1547,11/06/1971, p. 27.

${ }^{664}$ A edição desse Festival em 1969 teve enorme sucesso de público e foi alvo de diversos anúncios e matérias de Marcha: "Con sala colmada, se realiza esta noche el Festival Cinematografico de Marcha. Marcha, 24/01/1969, p. 24-25. "Otra edición del Festival con sala colmada", Marcha, núm. 1436, 07/02/1969, p. 25. Sobre esse tema, temos o seguinte capítulo, no prelo: "Os Festivais de Cinema de Marcha e seu papel na constituição de um circuito cultural de resistência política (Uruguai, 1967 e 1968)" In: MORETTIN, Eduardo (org.). Cinema e História: circularidades, arquivos e experiência estética. Porto Alegre: Editora Sulina, 2017

665 VILLAÇA, Mariana. "O 'cine de combate' da Cinemateca del Tercer Mundo (1969-1973)". MORETTIN, E.; NAPOLITANO, M.; KORNIS, M. (orgs) História e Documentário. Rio de Janeiro: Editora FGV, 2012, p. $237-272$.

${ }^{666}$ Em uma sessão ocorrida no teatro El Galpón, coordenada por Juan Gentil, previa-se a seguinte sequência de atrações, todas em homenagem à "combatividade revolucionária": a exibição de filmes sob o encargo da Cinemateca del Tercer Mundo, seguida de um recital de poesia com Leonor Álvarez e Antonio Larreta e, encerrando a noite, apresentação de música concreta e canto. TRONCONE, Carlos. "Cine, poemas". Marcha núm. 1505, 07/08/1970, p. 24.

667 "Trasnoche de hoy: cinema cubano del mejor en el Festival de Marcha". Marcha, núm. 1442, 28/03/1969, p. 27; "26 de Julio, trasnoche en El Galpón", Marcha núm. 1503, 24/07/1970, p. 25; “Cinemateca del Tercer Mundo presenta: Latinoamerica en lucha. Poemas, canciones, filmes.” Marcha núm. 1506, 14/08/1970, p. 27. 
políticas diferenciadas, que se ramificavam em apoio aos Tupamaros, ao Partido Socialista ou ao Partido Comunista, entre outras organizações. ${ }^{668}$

As ecléticas "Trasnoches" e os demais eventos apoiados ou geridos por Marcha compuseram um importante circuito cultural ${ }^{669}$ que envolvia não apenas artistas uruguaios como grupos e artistas de outros países latino-americanos, aderentes à cultura do protesto ${ }^{670}$. Vale frisar que artistas e intelectuais exilados ou cerceados pela conjuntura repressiva, existente no Brasil e na Argentina no final dos anos sessenta, também puderam contar com espaço significativo nas páginas de suas edições ou receber apoio para a realização de espetáculo. Marcha difundiu com destaque, por exemplo, a temporada de apresentações do espetáculo teatral Arena conta Zumbi (Augusto Boal/Gianfrancesco Guarnieri) encenado pelo grupo brasileiro Teatro de Arena, em janeiro de 1971, que nutria forte vínculos com o grupo uruguaio El Gapón ${ }^{671}$.

Assim, vemos que o circuito fomentado por Marcha e sua linha editorial estreitaram vínculos identitários regionais importantes, aproximando o Uruguai de seus vizinhos. Esses vínculos de claras conotações ideológicos se estenderam, inclusive, aos públicos dos países próximos: no final dos anos 1960 se estabeleceu uma espécie de fluxo de turismo cultural a Montevidéu (partindo principalmente de Buenos Aires e do sul do Brasil) freqüentado por um

\footnotetext{
668 Para um mapa completo das organizações de esquerda no Uruguai, ver REY TRISTÁN, Eduardo. A la vuelta de la esquina. La izquierda revolucionaria uruguaya. 1955 - 1973. Montevideo: Fin de Siglo. 2006. Há autores que destacam o peso preponderante do Partido Comunista na cena cultural uruguaia. Para compreender a força da cultura política comunista no Uruguai e os pontos de convergência e distanciamento com as outras organizações, principalmente os tupamaros, ver: DE GIORGI, Ana Laura. Las tribus de la izquierda: bolches, latas y tupas en los 60. Montevidéu: Fin de Siglo, 2011 e SILVA SCHULTZE, Marisa. Aquellos comunistas (1955-1973). Montevideo: Taurus, 2009.

669 Entendemos circuito cultual em sentido amplo, como "um conjunto compreendendo agentes produtores, meios de produção (tecnologia, recursos econômicos), produtos culturais, agentes distribuidores, dispositivo de troca e público, além de instâncias organizacionais relativas a todos ou à maior parte desses componentes (agências financiadoras, produtores privados, órgãos públicos de controle e estímulo, escolas de formação, etc.)" . COELHO NETTO, José Teixeira. Verbete: circuito cultural. Dicionário crítico de política cultural. SP: Fapesp/Iluminuras, 1997. Ver também GARCÍA CANCLINI, Néstor. Políticas Culturales en América Latina. México, Grijalbo, 1987.

${ }^{670}$ No campo específico do cinema há notas e reportagens, entre 1969 e 1972, sobre as visitas a Montevidéu feitas pelo documentalista Joris Ivens, o crítico de cinema alemão Peter Schumann, o cineasta chileno Miguel Littín, o jornalista italiano radicando na Venezuela Alberto Filippi, o cineasta Costa-Gavras entre outros nomes envolvidos na realização e difusão do chamado "cine de combate".

671 "Brasileños en El Galpón". Marcha núm. 1527, 08/01/1971, p. 23. GILBERT, Isabel "Arena cuenta y canta la emancipación". Marcha núm. 1528, 15/01/1971, p. 24. O semanário registraria, ainda esse ano, apresentações do grupo na Argentina: GALEANO, Eduardo. "Augusto Boal en Buenos Aires: la impotencia de Superman y la potencia del teatro". Marcha núm. 1571, 26/11/1971. Sobre as relações entre os grupos Teatro de Arena e El Galpón ver o seguinte trabalho por mim orientado: BODA, Diane. Teatro de Arena: concepção teatral e diálogos políticos latinoamericanos (1965-1972). Monografia de Conclusão de Curso em História (TCC), UNIFESP- Guarulhos, 2011.
} 
público universitário, politicamente engajado. Parte importante desse fluxo era garantida por cinéfilos interessados em prestigiar festivais e mostras de cinema político, abundantes no Uruguai, onde filmes então proibidos na Argentina e no Brasil se mostravam acessíveis sem cortes ou restrições. Esse fenônemo se evidenciou por ocasião das concorridas sessões do premiado filme argentino La Hora de los hornos, exibido com alarde em Montevidéu, no início de $1969^{672}$ e da estreia de filmes cubanos, ansiosamente aguardadas pelo público sulamericano 673 .

Acreditamos que a cultura de resistência difundida e alimentada pelo circuito em torno de Marcha, fruto da política cultural empreendida por sua direção e equipe em caráter ora mais, ora menos formal, fincou raízes profundas e conquistou um lugar fundamental na sociedade e na identidade uruguaia, sobrevivendo à ditadura e ressurgindo, com intensidade, no processo de redemocratização, ainda que com contornos adaptados à situação de derrota dos projetos de luta revolucionária. Isso nos parece sugerido pela permanência do discurso latinoamericanista no pós-ditadura, discurso que, como vimos, serviu como motor de revisão da velha imagem do país como "a Suíça da América Latina". Também nos parece sintomática a permanência de determinadas características da produção artística dos anos 1960 (como a denúncia social, o combativismo político, a proposta de reinterpretação da identidade nacional) em boa parcela da criação teatral, literária, cinematográfica e cancionista das décadas seguintes. Igualmente indicativos da hegemonia cultural de esquerda que se estabeleceu nesse período (anos 1960/70), e da inegável penetração de Marcha na sociedade uruguaia, são alguns dados do cenário que sucede a repressão a esse organismo: após o encerramento do semanário Marcha, em 1974, o público não ficou totalmente órfão ao poder contar com as edições dos Cadernos de Marcha produzidas no exílio e, finda a ditadura, no próprio país. Nesse mesmo momento, em que se vivia o início da transição democrática, surgiu o periódico Brecha (1985) com parte da equipe antiga de Marcha e perfil bastante semelhante àquele. A partir desses elementos, podemos vislumbrar, assumindo o risco da simplificação

672 "Primicia Continental: La hora de los hornos", Marcha núm. 1437, 14/02/1969, p.25. "Acontecimiento memorable: La hora de los Hornos en el Festival", Marcha núm. 1438, 28/02/1969, p. 25; WAINER, José. "En el programa del Festival de Marcha, La Hora de los Hornos y Canto de Protesta". Marcha núm. 1440, 14/03/1969, p. 27.; WAINER, José. "Cine latinoamericano: exito y persecución", Marcha núm. 1450, 30/05/1969, p. 25; "La Hora de los hornos para todo público, manãna en el Odeon", Marcha núm. 1451, 06/06/1969, p. 27.

673“Homenaje del Festival de Marcha al Cine Cubano", Marcha num. 1441, 21/03/1969, p. 27; "El 25 Ilega Lucía”. Marcha núm. 1502, 17/07/1970, p. 25. 
que o termo sugere, uma "linha de continuidade" desencadeada pela política cultural de Marcha e seu impacto na sociedade que nos parece material extremamente rico para a investigação histórica e para a discussão sobre as transformações na identidade uruguaia a partir dos anos 1960.

\section{Referências Bibliográficas}

ACHUGAR, Hugo \& CAETANO, Gerardo (orgs.). Identidad uruguaya: ¿̇mito, crisis oafirmación? 3a ed. Montevidéu: Trilce, 1992.

ALFARO, H. Navegar es necesario. Quijano y el Semanario Marcha. Montevideo: EBO, 1984.

COUTO, Cristiano Pinheiro de Paula. Intelectuais e exílios. Confronto de resistências em revistas culturais. Encontros com a Civilização Brasileira, Cuadernos de Marcha e Controversia (1978-1984) Tese de Doutorado em História, Porto Alegre: Universidade Federal do Rio Grande do Sul, 2013.

DE ARMAS, Gustavo; GARCE, Adolfo.Uruguay y su conciencia crítica. Intelectuales y política en el siglo XX. Montevidéu: Trilce, 1997.

DE GIORGI, Ana Laura. Las tribus de la izquierda. Bolches, latas y tupas en los 60. Comunistas, socialistas y tupamaros desde la cultura política. Montevideo: Fin de Siglo, 2011.

CAETANO, Gerardo; Rilla, José Pedro. El joven Quijano (1900-1933). Izquierda nacional y conciencia crítica. Montevideo: Ediciones de la Banda Oriental, 1986.

FERREIRA, André Lopes. A unidade política das esquerdas no Uruguai: das primeiras experiências à Frente Ampla (1958-1973), Tese de doutorado em História, UNESP - Assis (São Paulo), 2011.

GREGORY, Stephen. Intelectuals anda Left Politics in Uruguay 1958-2006. Frustrade Dialogue. Portland: Sussesx Academica Press, 2009.

LACRUZ, Cecilia. "La experiencia del semanario Marcha y el cine político en Uruguay". In: CABEZAS VILLALOBOS, O e ANSA GOICOECHEA, E. (orgs) Efectos de imagen. ¿Qué fué y qué es el cine militante? Santiago: LOM Ediciones / Universidad Metropolitana de Ciencias de La Educacion, 2014, p. 23-39.

MARCHESI, Aldo. El Uruguay inventado. La política audiovisual de la dictadura, reflexiones sobre su imaginario. Montevideo: Trilce, 2001.

MARCHESI, Aldo; Markarian, Vania; Rico, Álvaro \& Yaffé, Jaime. (orgs)El presente de la dictadura: Estudios y reflexiones a 30 años del Golpe de Estado en Uruguay. Montevidéu: Trilce, 2004. 
MARKARIAN, Vania. El 68 uruguayo. El movimiento estudiantil entre molotovs y música beat. Buenos Aires: Universidad Nacional de Quilmes Editorial, 2012.

MORAÑA, Mabel y MACHÍN, Horacio. (Eds) Marcha y America Latina. Pittsburgh: Instituto Internacional de Literatura Iberoamericana, 2003.

PADRÓS, Enrique Serra. Como el Uruguay no hay. Terror de Estado e Segurança Nacional. Uruguai (1968-1985): do Pachecato à ditadura civil-militar. Tese de doutorado em História, Porto Alegre, UFRGS, 2005.PANIZZA, Francisco. Batllismo y después. Pacheco, militares y tupamaros en la crisis del Uruguay batllista. Montevideo: Ediciones de La Banda Oriental, 1990.

PEIRANO BASSO, Luísa. Marcha de Montevideo y la formación de la conciencia latinoamericana a través de sus cuadernos. Buenos Aires: Ediciones B, 2001.

PINO, Mirian. "El semanario Marcha de Uruguay: uma genealogia de la crítica de la cultura en America Latina”. Revista Crítica Literaria Latinoamericana, XXVIII, 56; (2002), p. 141-156.

PIÑEYRÚA, Pilar. "Las tapas y titulares del semanário Marcha: una puerta grande a la argumentación." Buenos Aires, IV Jornadas de Historia de las Izquierdas, 14-17 noviembre 2007.

RAMA, Angel. La generación crítica. Montevideo: Editorial Arca, 1972.

RAMA, Angel. "La lección intelectual de Marcha". Cuadenos de Marcha, 2ª série, num. 19, maijun 1982, p. 53-58.

REAL DE AZÚA, Carlos. “Carlos Quijano (1900)" In: Antología del Ensayo Uruguayo Contemporáneo, Tomo II. Departamento de Publicaciones de la Universidad de la República, Montevideo, Uruguay, 1964, p. 319-328.

REIS, Mateus Fávaro. Políticas da leitura, leituras da política: uma história comparada sobre os debates político-culturais em Marcha e Ercilla (Uruguai e Chile, 1932-1974). Tese de doutorado. Belo Horizonte: Universidade Federal de Minas Gerais, 2012.

REY TRISTÁN, Eduardo. A la vuelta de la esquina. La izquierda revolucionaria uruguaya. 1955 - 1973. Montevideo: Fin de Siglo. 2006

ROCCA, Pablo. 35 años en Marcha. Crítica y literatura en Marcha y en el Uruguay (1939-1974). Montevideo: Intendencia Municipal de Montevideo, 1992.

SILVA SCHULTZE, Marisa. Aquellos comunistas (1955-1973). Montevideo: Taurus, 2009

VILLAÇA, Mariana. "O 'cine de combate' da Cinemateca del Tercer Mundo (1969-1973)". MORETTIN, E.; NAPOLITANO, M.; KORNIS, M. (orgs.) História e Documentário. Rio de Janeiro: Editora FGV, 2012, p. 237-272. 
VILLAÇA, Mariana O documentário como fonte: a visão da ditadura uruguaia no cinema de Mario Handler. In: Mariana Villaça e Maria Ligia Coelho Prado. (Org.). História das Américas: fontes e abordagens historiográficas. São Paulo: Humanitas/CAPES, 2015, p. 85-113.

Recebido em 20 de janeiro de 2017. Aprovado em 04 de junho de 2017. 